\title{
HISTÓRIAS DE MULHERES E EPISTEMOLOGIA DAS "PIABAS": REFLEXÕES DECOLONIAIS DE GÊNERO E ECOLOGIA EM CONTEXTOS DE MIGRAÇÃO
}

\author{
Violeta Holanda ${ }^{\mathrm{i}}$ \\ Stela Rosa ${ }^{\text {ii }}$
}

\begin{abstract}
Resumo: O artigo tem por objetivo apresentar algumas reflexões críticas decoloniais de gênero e ecologia, a partir da troca de saberes e experiências feministas - histórias de mulheres e epistemologia das "piabas" - em contextos de migração que envolve a região nordeste do Brasil. Considera o diálogo entre o humano e a natureza, aproximando-se da perspectiva filosófica do "Bem Viver" no entendimento da relacionalidade e da complementariedade entre os seres vivos. O agir feminino e a fluidez animal são aproximados na relação ecológica da (re)produção do ciclo da Astyanax bimaculatus, peixe popularmente conhecido como "piaba". Trata-se de uma reflexão mediada pela autoetnografia que incorpora a experiência pessoal das pesquisadoras, interagindo com a realidade sociocultural investigada. Expressa relatos históricos e contingente de si, intercruzando práticas cotidianas e o cuidado com o mundo. Um trabalho de memória cujos fios que compõem sua trama entrelaçam passado e presente dando relevo às experiências coletivas que singularizam os corpos humanos e não humanos.
\end{abstract}

Palavras-Chave: Gênero; Decolonialidade; Ecologia; Migração; Autoetnografia.

\section{WOMEN STORIES AND EPISTEMOLOGY OF THE "PIABAS": DECOLONIAL REFLECTIONS OF GENDER AND ECOLOGY IN MIGRATION CONTEXTS}

\begin{abstract}
The article presents some critical decolonial reflections about gender and ecology based on the exchange of feminist knowledge and experiences - women's stories and "piabas" epistemology - in migration contexts involving the northeastern region of Brazil. It considers the dialogue between human and nature, approaching the philosophical perspective of "Buen Vivir" in the understanding of the relationality and complementarity among living beings. The feminine action and animal fluidity are approximated in the ecological relation of the (re)production of the cycle of Astyanax bimaculatus, a fish popularly know as "piaba". It's a reflection mediated by the autoethnography that incorporates the researchers' personal experience, interacting with the sociocultural reality studied. It expresses historical and contingent reports of themselves, intercrossing daily practices and caring for the world. A work of memory whose weft involves past and present, giving prominence to the collective experiences that singularize human and nonhuman bodies.
\end{abstract}

Keywords: Gender; Decoloniality; Ecology; Migration; Autoetnography.

Revista Interinstitucional Artes de Educar. Rio de Janeiro, V. 4 N. 3 - pag 679-700 (out/2018 - jan/ 2019) 


\section{Introdução}

A produção deste artigo foi pensada a partir de um (re)encontro das autoras na cidade de Florianópolis, na ocasião do $18^{\circ}$ Congresso Mundial IUAES (International Union of Anthropological), de 18 a 20 de julho de 2018, cujos eixos temáticos foram a decolonialidade, o feminismo e as relações étnico-raciais. Na programação da Rede Global de Antropologia Feminista, Mara Viveros Vigoya profere a palestra magna intitulada "Entre la extraversión y las epistemologías "nuestramericanas": el lugar de la producción antropológica com enfoque de género", cujo enfoque chama atenção para a importância e necessidade da produção feminista em contextos locais, que considere as culturas e as perspectivas das relações de gênero nos espaços latino-americanos.

De imediato, os olhos se entrecruzaram e o pensamento se manifesta em palavras “é preciso ser muito piaba mesmo!". A ideia remete ao sentimento de pertença cearense, que constitui mulheres em movimento - pequenas, dinâmicas, que agem coletivamente na (ou contra) correntezas no fluxo contínuo da busca pela sobrevivência. Neste sentido, objetivamos apresentar aqui algumas reflexões críticas em perspectivas decoloniais de gênero e ecologia, a partir da troca de saberes e experiências feministas - histórias de mulheres e epistemologia das "piabas" - em contextos de migração que envolve a região nordeste do Brasil. O agir feminino e a fluidez animal são aproximados na relação ecológica da (re)produção do ciclo da Astyanax bimaculatus, peixe popularmente conhecido como "piaba".

É importante considerar o que Spivak (2010) problematiza sobre os diálogos e expressividade dos contextos colonizados, onde a/o intelectual assume o compromisso de articulação entre a/o "subalterna/o" e o pensar colonizador, evidentemente, se posicionando a favor da visibilidade do agir/pensar historicamente subalterizado. Segundo a autora,

O subalterno não pode falar. Não há valor algum atribuído à "mulher" como um item respeitoso nas listas de prioridades globais. A representação não definhou. A mulher intelectual como uma intelectual tem uma tarefa circunscrita que ela não deve rejeitar com um floreio (SPIVAK, 2010: 126).

Neste contexto, nos identificamos ora com o papel de mediadoras da produção acadêmica que comunica o modo de ser/viver da/o "outra/o", ora com a ação política de nos 
expressamos diretamente a partir das nossas próprias experiências, convergidas pelo conhecimento científico, mas também por nossas subjetividades nativas.

Tal perspectiva converge com o modelo de produção acadêmica feminista apontado por Cláudia Fonseca (2006) que privilegia a incorporação da subjetividade na análise científica, tem o foco na experiência, a ênfase na prática (que não vem mais a reboque a teoria) e a historicização dos próprios conceitos científicos (FONSECA, 2006:16). Por outro lado, coaduna também com a reflexão crítica e criativa decolonial do gênero, apresentada por María Lugones $(2008,2014)$ pela necessidade da releitura da própria modernidade capitalista colonial, que considere as questões ecológicas, econômicas, políticas, espirituais e a própria produção do conhecimento intercruzando às práticas cotidianas e o cuidado com o mundo (LUGONES, 2014: 935).

Lugones (2014) ainda nos chama atenção para a tendência dicotômica da colonialidade do gênero, cuja distinção principal se fundamenta na separação entre o humano e o não humano. Segundo a autora,

Começando com a colonização das Américas e do Caribe, uma distinção dicotômica, hierárquica entre humano e não humano foi imposta sobre os/as colonizados/as a serviço do homem ocidental. Ela veio acompanhada por outras distinções hierárquicas dicotômicas, incluindo aquela entre homens e mulheres. Essa distinção tornou-se a marca do humano e a marca da civilização. Só os civilizados são homens ou mulheres. Os povos indígenas das Américas e os/as africanos/as escravizados/as eram classificados/as como espécies não humanas - como animais, incontrolavelmente sexuais e selvagens (LUGONES, 2014: 936).

A relação entre natureza e cultura é discutida na produção intelectual feminista com fins de problematizar as desigualdades de gênero historicamente reproduzidas pelo padrão colonial ocidental. A contribuição do feminismo decolonial emerge no processo de radicalização dessa compreensão no sentido de enquadrar o debate racial e denunciar as gravíssimas violações da "missão civilizatória" contra os povos originários da América e Caribe e a população escravizada africana. Neste sentido, o feminismo decolonial se inscreve a partir do olhar crítico e da resistência à colonialidade do gênero.

Aqui buscamos contribuir com as reflexões críticas decoloniais de gênero incorporando o olhar sobre a ecologia, no entendimento da relacionalidade e da 
complementariedade entre os seres vivos.

\section{Metodologia}

A produção do conhecimento científico na perspectiva crítica feminista incide na denúncia do caráter ideológico, colonial, racista e sexista em que se constituiu a ciência. Retoma à atenção ao discurso humanista da teoria moderna que cunhou as noções de Sujeito e Identidade numa perspectiva essencialista e universalista, desconsiderando as especificidades de gênero, classe, raça, etnia, orientação sexual, etc., de diferentes sujeitos/as que ocupam outras fronteiras políticas e geográficas. Segundo Margareth Rago (2006),

(...) o saber ocidental opera no interior da lógica da identidade, valendo-se de categorias reflexivas incapazes de pensar a diferença. Em outras palavras, atacam as feministas, os conceitos com que trabalham as Ciências Humanas são identitários e, portanto, excludentes. Pensa-se a partir de um conceito universal de homem que remete ao branco-heterossexual-civilizado-doPrimeiro-Mundo, deixando-se de lado todos aqueles que escapam deste modelo de referência. Da mesma forma, as práticas masculinas são mais valorizadas e hierarquizadas em relação às femininas, o mundo privado sendo considerado de menor importância frente à esfera pública, no imaginário ocidental. Portanto, as noções de objetividade e de neutralidade que garantiam a veracidade do conhecimento caem por terra, no mesmo movimento em que se denuncia o quanto os padrões de normatividade científica são impregnadas por valores masculinos, raramente filóginos (RAGO, 2006:25).

Neste contexto, evidenciamos a necessidade de uma produção do conhecimento plural, feminista e decolonialiii, que assuma e evidencie o "lugar de fala"iv de quem o produz, e que considere aqui os marcadores sociais das diferenças de gênero, classe, étnico-racial e de origem em sua relação particular ou interseccional ${ }^{\mathrm{v}}$.

Rago (2006) adverte que a epistemologia feminista inaugura um campo e uma forma de produção do conhecimento que altera a relação sujeito-objeto, questionando o alcance universal, racional e objetivo como modelo único de produção da ciência. Evidencia-se, portanto, a dimensão subjetiva, emotiva e intuitiva, superando a divisão corpo/mente, sentimento/razão. Para nós, interessa ainda mencionar a superação da divisão humano/não humano, considerando a necessidade de se pensar a produção do conhecimento e da vida a partir da relação do humano com a natureza, e sua própria sustentabilidade no planeta. Ainda 
segundo a autora,

(...) o feminismo propõe uma nova relação entre teoria e prática. Delineia-se um novo agente epistêmico, não isolado do mundo, mas inserido no coração dele; não isento e imparcial, mas subjetivo e afirmando sua particularidade. Ao contrário do desligamento do cientista em relação ao seu objeto de conhecimento, o que permitiria produzir um conhecimento neutro, livre de interferências subjetivas, clama-se pelo envolvimento do sujeito com seu objeto. Busca-se uma nova idéia da produção do conhecimento: não o cientista isolado em seu gabinete, testando seu método acabado na realidade empírica, livre das emoções desviantes do contato social, mas um processo de conhecimento produzido por indivíduos em interação, em diálogo crítico, contrastando seus diferentes pontos de vista, alterando suas observações, teorias e hipóteses, sem um método pronto. Reafirma-se a idéia de que o caminho se constrói caminhando e interagindo (RAGO, 2006: 32-33).

Assim, encontramos na autoetnografia o método possível de incorporar a experiência pessoal das pesquisadoras interagindo com a realidade sociocultural investigada. Buscamos expressar relatos históricos e contingente de si, intercruzando práticas cotidianas e o cuidado com o mundo. Um trabalho de memória cujos fios que compõem sua trama entrelaçam passado e presente dando relevo às experiências coletivas que singularizam os corpos humanos e não humanos.

O termo "auto-etnografia" foi utilizado inicialmente pelo antropólogo Hayano em 1979, depois, no início dos anos de 1980, esta abordagem metodológica começou a ser desenvolvida e definida como um método de pesquisa referendado pelo Departamento de Fenomenologia, Etnometodologia e Sociologia Existencial na pós-graduação da Universidade de Chicago. Jones et al (2013) explica que a autoetnografia propõe a pesquisa social numa prática menos alienadora, em que o pesquisador não precisa suprimir sua subjetividade. Expressa-se pela forte reflexividade, que representa a consciência de si e a reciprocidade entre o pesquisador e seu campo de pesquisa, o que conduz uma introspecção guiada pelo desejo de entender ambos. Portanto, revela-se uma postura perante o texto, pois não existe neutralidade quando escrevemos algo, assim como quando lemos nós trazemos todas as nossas relações para as páginas (JONES,SH et al, 2013: 229).

Enfim, Inspiradas pela escrita de Rubem Alves (1999) que nos fala sobre a importância da analogia ${ }^{\mathrm{vi}}$ no exercício da produção científica, faremos uma aproximação do ciclo de vida das piabas com as experiências autoetnográficas de nós, autoras.

Revista Interinstitucional Artes de Educar. Rio de Janeiro, V. 4 N. 3 - pag 679-700 (out/2018 - jan/ 2019) 


\section{Do ciclo das piabas}

Segundo o Novo dicionário da língua portuguesa, piaba, piava, piau, aracu, manjuba e lambari são termos sinônimos que designam vários tipos de peixes encontrados nos rios do Brasil. "Piaba" e "piava" procedem do termo tupi pi'awa, que significa "pele manchada". "Piau" procede do termo tupi pi'au, "pele manchada". "Aracu" procede do termo tupi ara'ku. Pode-se encontrar as piavas em canais de rios e em cachoeiras. É um peixe de água doce. Também é um peixe que gosta de água corrente e límpida. Tem cor brilhante, prateada, boca pequena, porém possui dentes fortes e capazes de arrebentar anzóis fracos. Costuma nadar muito em busca de comida. Suas preferências são por vegetais, larvas de insetos, além de pequenos peixes. Anualmente, as piabas-vermelhas (Leporinus copelandii Steindachner) efetuam uma migração em direção à nascente para reprodução e, depois, retornam rio abaixo (FERREIRA, 1986).

Em outras referências, é possível identificar aproximadamente uma centena desta espécie. Este peixe nativo pode ser encontrado ao longo dos rios, lagoas e represas de toda América Latina, da fronteira do México com os Estados Unidos até próximo à Patagônia no extremo sul, excetuando-se em algumas regiões do Chile, por apresentar um clima excessivamente frio. Assim, as piabas se fazem presentes por todo continente latinoamericano, manifestando como maior característica um ciclo altamente reprodutivo, pausado apenas no período do inverno o seu processo de fecundação/reprodução da vida (GLOBO, 2018). Nas tradições de matrizes africanas, é um ser de Oxum, a deusa negra das águas doces, da beleza e da fertilidade.

A fecundação da piaba é tão expressiva, que seus alevinos podem sofrer longas migrações causadas pelo contato direto com aves (em duas garras) que circulam entre um lugar e outro em busca de alimento. Isso contribui para a grande adaptação deste ser vivo em distintas águas doces por extensos territórios. Ademais, as piabas também se movimentam no leito das águas correntes, contra ou a favor, sempre com bravura em busca de melhores condições no habitat natural para manter a sua presença.

Por longos períodos de convivência com os seres humanos, as piabas pareciam livres e "invisíveis" no reino do Homo sapiens. Aparentemente, eram seres pouco atrativos. Marcavam presença constante em seus territórios interagindo, sobretudo, com as crianças no

Revista Interinstitucional Artes de Educar. Rio de Janeiro, V. 4 N. 3 - pag 679-700 (out/2018 - jan/ 2019) 
aprendizado da arte de pescar.

Relatos também figuram a lenda de que "comer piaba viva quando criança" facilitava a habilidade do nado com agilidade. Mas, as piabas sempre foram pouco valorizadas do ponto de vista do mercado, da venda de peixes como mercadoria de troca.

No entanto, recentemente, esta realidade vem se transformando. A objetificação da natureza pelo humano encontra uma razão de mercado para a (re)produção controlada das piabas. Empresas do ramo da piscicultura instrumentalizam a criação do peixe como objeto de negócios rentáveis, utilizando-se da reprodução artificial por meio de hormônios, e da criação

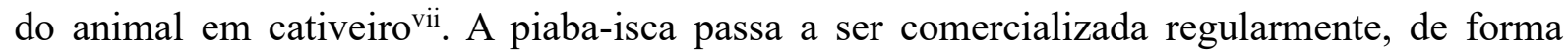
ampliada, e categorizada como carne de supermercado para o consumo humano - produto gourmet.

Ora, a relação do humano com as piabas muda de sentido. A natureza agora é instrumento e objeto de utilização/exploração do mercado, sendo intermediada pelo conhecimento científico e tecnológico. O curso natural e biológico das piabas muda de rota e a vida animal é aprisionada deliberadamente para o domínio do consumo humano. Diante de tal cenário, resta-nos problematizar do ponto de vista ético e ecológico a relação de exploração humano versus natureza, a relação que aprisiona, altera rotas, coisifica e mata.

Pensar a relacionalidade e a complementariedade entre todos os seres vivos - humanos e não humanos, tem sido um esforço da filosofia do "Bem Viver", inspirada na sabedoria ancestral e no modo de vida ameríndio em contextos andino e amazônico. Em contraposição ao modelo de desenvolvimento ocidental colonial, seu ponto de partida são as distintas maneiras de ver a vida e sua relação com a Pacha Mama, a Mãe Terra. O "Bem Viver" inaugura uma cosmovisão de mundo baseada nos Direitos Humanos e nos Direitos da Natureza. Segundo o autor Alberto Acosta (2016),

O Bem Viver propõe uma cosmovisão diferente da ocidental, posto que surge de raízes comunitárias não capitalistas. Rompe igualmente com as lógicas antropocêntricas do capitalismo enquanto civilização dominante e com os diversos socialismos reais que existiram até agora - que deverão ser repensados a partir de posturas sociobiocêntricas e que não serão atualizadas simplesmente mudando sobrenomes. Não esqueçamos que socialistas e capitalistas de todos os tipos se enfrentaram e ainda se enfrentam no quadrilátero do desenvolvimento e do progresso (ACOSTA, 2016: 72). 


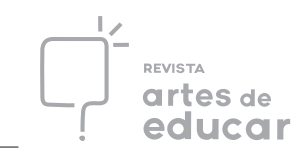

Aqui, interessa-nos um elemento-chave destacado pela filosofia do Bem Viver: "o centro das atenções não deve ser apenas o ser humano, mas o ser humano vivendo em comunidade e em harmonia com a Natureza" (ACOSTA, 2016:27). Tal perspectiva nos inspira pensar à vida de uma maneira sustentável e ecologicamente equilibrada, não consumista e mercantilizada, garantindo uma existência digna para todos e a própria sobrevivência da espécie humana e do planeta. Assim, compartilhamos nossas experiências de vida e as relações de alteridades no contexto de nossas autobiografias refletidas a partir do pertencimento cearense e, de uma forma mais abrangente, nordestino.

\section{Sociabilidades de uma infância}

Inicialmente, é importante situar o difícil exercício que é falar sobre si. Obviamente, a possibilidade para tal empreendimento faz sentido se nele estiver contida a relação do eu com a/o outra/o, do eu em coletividade, do eu em movimento. Assim, na intenção de relatar as memórias e lembranças de um passado recente, minha infância nos anos 70, busco relacionála à ancestralidade (minha e a "terra" em que nasci) a partir da troca de saberes e experiências que "minha avó", sim era assim que eu a chamava, que minha avó paterna Maria significa no cenário do sítio Candéia-Pilar, localizado na zona rural do município de Baturité, Ceará.

O sítio Candéia-Pilar é o local de encontro e partida destas memórias. Nele as cores, cheiros, sabores, sons e silêncio continuam presentes na lembrança de meu passado. Do encontro inspirador, seguindo a pequena trilha molhada, estreita, entre vegetação e animais que se manifestam, rumo ao riacho olho d'água para lavar roupas ou simplesmente tomar banho nas manhãs quentes e ensolaradas, a imagem e o movimento delas - as piabas, sempre presentes naquele lugar, numerosas, agitadas, traçando caminhos na (ou contra) a correnteza.

Nasci em 03 de outubro de 1974. O parto foi bem difícil, via fórceps. Minha mãe era "pequena" para o tamanho da filha que gerara. Sem assistência médica adequada ela teve sequelas no aparelho reprodutor após o parto e, desde então, sou fillha única e primeira neta de uma família de quatro filhos homens (meus tios). Portanto, havia muita expectativa de minha chegada e, conforme tradição familiar, a planta escolhida por meu pai para celebrar minha existência foi a laranjeira, com sua fruta doce, saborosa, suculenta e cheia de espinhos, bem abundante na região.

Revista Interinstitucional Artes de Educar. Rio de Janeiro, V. 4 N. 3 - pag 679-700 (out/2018 - jan/ 2019) 
No sítio Candéia, a árvore que representava meu tio mais velho era uma frondosa jaqueira, bem em frente a pequena casa do sítio, com caule largo e fruto exuberante. Talvez, a escolha da planta se relacionasse com o gênero/personalidade do indivíduo que nascera. Fiquei feliz por minhas laranjeiras. Meu nome, Violeta Maria, foi em homenagem às minhas avós Violeta (avó materna, em memória) e Maria (avó paterna). Fui batizada na igreja matriz tendo como padrinhos meus avós paternos, Antônio e Maria.

Baturité está localizado na Região Serrana do Maciço de Baturité. Em tupi-guarani significa literalmente: "o monte verdadeiro, legítimo" (ibitira+eté). A região foi historicamente habitada pelas etnias indígenas Potyguara, Jenipapo e Kanindé. Baturité recebeu diversas expedições militares e religiosas de ocupação portuguesa a partir do século XVII. A missão intitulada de Nossa Senhora da Palma é o marco de intensificação da ocupação missionária dos Jesuítas com finalidade de aldeamento dos indígenas. Por causa do clima ameno, da água e vegetação em abundância, Baturité e outros municípios da região serviram de refúgio para populações sertanejas castigadas pela seca, que vinham de municípios como Canindé e Quixadá. Um marco da presença católica no município é o grupo de igrejas, conventos e mosteiros que ainda resistem ao tempo e alguns deles convertidos em hospedarias nos dias atuais (BATURITÉ, 2018).

Durante o século XIX, chega do Pará as primeiras mudas de café na região. A atividade econômica é impulsionada pela produção cafeeira chegando a representar na época $2 \%$ de toda a produção brasileira. Há relatos de que o café de Baturité foi consumido nas principais cafeterias francesas. Logo, o fluxo produtivo expandiu acessos e a construção da primeira ferrovia no Estado do Ceará, em 1870, constituindo juridicamente a Estrada de Ferro de Baturité.

$\mathrm{O}$ processo de modernização da cidade acontece em meados do século XX, com o fortalecimento do movimento religioso da Ação Católica, encabeçado pelo vigário local Monsenhor Manoel Cândido e pelo Comendador Ananias Arruda. A família Arruda mantém, hoje, o poder político no município. Desse movimento católico surgem vários prédios religiosos na cidade como: o Colégio Nossa Senhora Auxiliadora (1934), o Colégio Salesiano Domingos Sávio (1932), o Círculo Operário Católico de Baturité (1924) e a Escola Apostólica dos Jesuítas (1927). Tal movimentação propicia o aquecimento do comércio local, a vida estudantil nos colégios salesianos e o surgimento de uma classe média composta por 


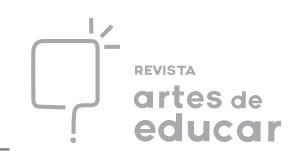

imigrantes de diferentes municípios do Ceará (BATURITÉ, 2018).

Meus avós paternos, tios e pai nasceram todos na Serra de Baturité. Provavelmente, descendentes indígenas. Minha mãe, do sertão de Quixeramobim. Veio adotada pelos tios paternos para Baturité após o falecimento precoce de minha avó. Eles eram comerciantes e minha mãe descendente de sertanejos e avô português. Ela teve acesso a educação no colégio salesiano de freiras (feminino) e meu pai no seminarista de padres (masculino). Nos anos 70, além do comércio, da vida religiosa e estudantil, a produção da agricultura familiar era o principal sustento dos pequenos e médios agricultores estabelecidos na Serra. Meu avô produzia banana para a venda no comércio local e em Fortaleza, além de manter uma diversificada plantação de frutas e verduras para subsistência. O pequeno sítio do Candéia sempre produziu bons frutos e a movimentação da chegada e partilha dos bens alimentícios também está na minha memória.

Meu avô, responsável pela produção, e minha avó, pela gestão e partilha dos bens. De herança, uma casa nos fundos do Círculo Operário Católico de Baturité, localizada na Rua São José, próximo à igreja matriz e em frente à vila denominada Redenção ${ }^{\text {viii }}$. A casa sempre foi muito movimentada pelas pessoas que vinham da Serra e tinham aquele espaço como ponto de apoio (para ir ao médico, à feira, ao comércio, etc), ou pelos vizinhos da própria rua, que a todo instante demandavam ajuda, sobretudo, doação de alimentos. Era uma casa simples, mas com fartura de alimentos e solidariedade ao próximo.

Mas, na vida cotidiana durante a infância, a presença marcante sempre foi de minha avó Maria, no saber-fazer e no ensinar-aprender. Das heranças históricas daquele lugar, o cheiro de café torrado por toda a casa e do pilão no quintal como instrumento de transformação do alimento no sustento da vida. A castanha torrada, a laranja espremida na boca, o ovo da galinha caipira cozido, a tapioca grossa feito beiju, o doce de banana em rodela caramelizado como nunca encontrei igual. A companhia nas longas procissões em alusão aos santos católicos. Sentia que a formação cristã se consolidada paulatinamente naquela cidade tomada por missões jesuítas e salesianas. A disciplina do corpo/mente, a obediência, a crença, a passividade e a higienização constituíram valores/conhecimentos de referência assimilados naquele período.

No início da adolescência, a separação de meus pais ocasiona uma significativa ruptura com meu lugar de origem e com as relações afetivas que nele se constituíram. Eu e

Revista Interinstitucional Artes de Educar. Rio de Janeiro, V. 4 N. 3 - pag 679-700 (out/2018 - jan/ 2019) 688 
minha mãe migramos para a capital Fortaleza, sem pistas de endereço, permaneci pelos próximos doze anos sem nenhum contato com a terra natal e nem com os parentes de filiação paterna.

Um novo horizonte de ambiente urbano se manifesta nos espaços em que passo a circular, sejam eles: na escola, no centro, nas avenidas, nos clubes, nos ônibus, nas praias e nos bairros centrais e periféricos da cidade. Sim, pois nos anos 80, a inflação desenfreada e os ajustes constantes nos valores dos aluguéis exigiam que nos mudássemos a cada seis meses de nossa moradia, de bairro em bairro da capital cearense. Morei nos quatro cantos desta cidade.

Por outro lado, o maior desafio sempre foi a ambientação dos valores, costumes e modos de vida citadinos. A correria do dia a dia, a competição e a concorrência, o individualismo, o modo de vestir-se e a aparência física, a precarização das vidas, sobretudo, das vidas das mulheres "separadas" que tentavam sobreviver "livremente" naquele lugar. A contra-correnteza se fortalecia quando a estrutura sócio-econômica endurecia. Sem emprego e renda fixos, não era fácil sobreviver em tal ambiente, era preciso estar atentas e fortes, não tínhamos tempo para temer a morte. Nadando contra-correntezas, porém, freneticamente lutando pela vida.

\section{Dos movimentos das piabas e dos nordestinos}

A migração é um ponto confluência entre os nordestinos e as piabas. Ambos movimentam-se a favor ou contra corrente para garantir a vida. Enquanto as piabas se deslocam pela América Latina, fronteira do México com os Estados Unidos até próximo à Patagônia no extremo sul, o fluxo interno da população humana da região do Nordeste do Brasil espalha-se pelo país, concentrando-se, com mais prevalência, em locais com abundante oferta de trabalhos. No século XIX, o rumo era a Amazônia, na época do primeiro ciclo da borracha que necessitava de mão-de-obra para extração de látex usado na produção borracha. Movimento que se repete nos anos de 1940. A partir da década de 1950, com o crescente processo de industrialização, São Paulo e Rio de Janeiro passam a ser os destinos. Na esperança de uma vida melhor, homens e mulheres se arriscavam no pau de arara, caminhões cobertos com lonas e bancos de madeiras improvisados, movidos pela esperança de uma vida melhor. Nesse mesmo período, registra-se deslocamento para outro destino, o Centro-Oeste. 
Seduzidos pelo plano de empurrar o Brasil para frente - fazer em cinco anos o não realizado em 50 - nordestinos vão trabalhar na construção de Brasília. Há ainda aqueles que se deslocavam dentro da região.

A esperança de vida farta conjugada ao descaso político, que marca o processo desigual de desenvolvimento regional do país, ainda move nordestinos. Atualmente, entre os diversos destinos, dois têm relevância para a nossa reflexão: Santa Catarina, publicizada como a Ilha da Magia, que passa a fazer parte da rota migratória, especialmente no período da alta estação do turismo; e o Pará, estimulado pelo crescimento do agronegócio.

Nas análises acerca do êxodo de nordestinos, há duas perspectivas analíticas que se intercruzam: a neoclássica, que aponta como razões a busca por trabalho, por melhores oportunidades e salário; e a histórico-estruturalista, que defendem que o fluxo migratório foi decorrente do processo de industrialização. (OLIVEIRA \& JANNUZZI, 2005). Deslocandose dessas interpretações e estabelecendo diálogos entre Butler (2015) e Foucault (1999) podemos pensar o processo migratório do Nordeste como parte da gestão biopolítica de uma população, distribuída em um território permeado por diferenças. Segundo Foucault (1999), a biopolítica vai instalar mecanismos de poder com o fim de controlar ou modificar fenômenos internos, uma dinâmica que visa

estabelecer mecanismos reguladores que, nessa população global com seu campo aleatório, vão poder fixar um equilíbrio, manter uma média, estabelecer uma espécie de homeostase, assegurar compensações; em suma, de instalar mecanismos de previdência em torno desse aleatório que é inerente a uma população de seres vivos, de otimizar(...) destinados em suma a maximizar forças e a extraí-las, mas que passam por caminhos inteiramente diferentes (FOUCAULT, 1999, P. 294).

Pode-se assim compreender a migração como um mecanismo de gerir a movimentação da população para determinados lugares e fins, num cenário em que se tem, de um lado, focos de desenvolvimento em alguns estados, nos quais se concentram investimentos públicos e privados, especialmente o Sudeste; de outro, espaços considerados estagnados do ponto vista econômico, situação alimentada pelas constantes secas e pela herança dos efeitos da escravidão que se perpetuam no Nordeste, região na qual se concentra, até hoje, parcela significativa da população negra, que totaliza $74,6 \%$, e concentra o maior índice de pobreza, 
afetando 43,5\% da população (IBGE, 2017). Assim, o processo de migração constitui-se como forma de gerir fenômenos como a seca e a fome e o desenvolvimento nacional desigual, contando com estímulo do poder público para a movimento da população dentro do território nacional.

As reflexões de Butler (2015, p.46) nos ajudam a pensar que o imbricamento entre as questões ambientais, sociais e políticas produz efeitos diferenciados na gestão da precariedade, condição compartilhada por humanos e não humanos, pois ambos dependem do mundo exterior para sua sobrevivência e qualidade. Para a autora, as vidas são, por definição, precárias: podem ser eliminadas de maneira proposital ou acidental; sua persistência não está, de modo algum garantida. Em certo sentido, essa é uma característica de todas as vidas, e não há como pensar a vida como não precárias. Portanto, toda vida estabelece vínculo de dependência com as relações de poder, que produzem o lugar de aparição na esfera pública e os discursos que atuam como diferenciador das vidas. Tais discursos geram ontologias específicas de sujeito, maximizando a precariedade para alguns e, minimizando, para outros. A questão que se coloca é procurar entender o que leva alguns seres a ter mais valor que outros, quais as normas que constituem esses sujeitos, produzindo os enquadramentos por meio dos quais são reconhecidos.

Nesse sentido, mesmo que as análises de Butler (2015) sejam direcionadas para dar uma resposta crítica às guerras do mundo contemporâneo, levando em consideração, principalmente, o ponto de vista normativo e o enquadramento seletivo e diferenciado da violência, as categorias de enquadramento e precariedade ajudam a compreender as molduras que compõem a percepção da vida precária do nordestino em outras regiões do país e podem contribuir para pensar quais os mecanismos que acentuam a precariedade de determinadas vidas, desmontar as molduras que enquadram os corpos nordestinos hierarquizados em condições de inferioridade para que se possa pensar ações de resistência que garantam o direito à sobrevivência e à prosperidade.

\section{A construção de singularidades coletivas}

A história da minha geração, como a de vários nordestinos, é marcada pelo processo de migração e pela ditadura. Cheguei ao mundo em 1967. Eram os tempos de chumbo: de 


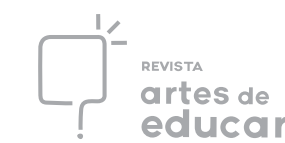

desaparecimento, assassinatos confinamento e genocídio de todos aqueles que representavam perigo ao sistema - os denominados comunistas, homossexuais, indígenas, negros. Enquanto muitos brasileiros se exilavam em outros países para fugir da violência ou buscavam desesperadamente por familiares desaparecidos, via crucis que ainda não terminou para muitas delas, para os meus pais, Juarez e Neuza, a vida corria na normalidade da ordem, (des)aquietada pela minha chegada, filha do meio. Nasci cinco anos depois do meu irmão mais velho, e cinco antes da mais nova.

Meu pai integra os índices dos movimentos migratórios de nordestinos na década 1950. Diferente de outros conterrâneos, como os irmãos da minha mãe que foram tentar a vida no Sudeste, os minguados recursos familiar não possibilitavam esse trajeto. A viagem precisou ser encurtada. Meu pai migrou de São José do Peixe, no Piauí, para Fortaleza, no Ceará, local onde conheceu minha mãe, Neuza, nascida em Brejo Santo, um pequeno município do interior do Ceará, fronteira com Estado de Pernambuco, mas que no imaginário da minha mãe fica próximo de Salvador, cidade onde tinha morado antes de ir para Fortaleza.

Vidas marcadas por diferentes traçados genealógicos. Meu pai, de ascendência indígena pelo lado materno, origem que foi apagada e jamais publicizada, e de português, pelo lado paterno, trazia nos ombros a responsabilidade de trabalhar e estudar e assim criar condições materiais para cumprir a missão: trazer a família para capital. Minha mãe, filha de pequenos agricultores, com ascendência portuguesa, estava na capital para continuar os estudos e tentar ingresso na universidade. O casamento e o nascimento dos filhos atrapalharam os planos, e a vida foi se improvisando: trabalharam na fabricação de bebidas, venda de ovos e conseguiram certa estabilidade financeira no ramo dos livros. Viraram livreiros, como era chamado na época os vendedores ambulantes que se aventuravam a vender essa mercadoria, à prestação, de porta em porta. Em meados dos anos 1990, com o surgimento de livrarias bem estruturadas, o negócio familiar faliu, e eles partiram para novas aventuras: fabricação e comercialização de peças íntimas. Com ajuda da família do lado materno, conseguiram adquirir a sonhada casa própria e imóveis em bairros do subúrbio, o que lhes garantiu investir na educação dos filhos.

Se o que levou meu pai a migrar foi a fome, a seca e a falta de perspectiva de "progresso", o meu deslocamento tem como pano de fundo a ditadura e os papéis desiguais imposto às mulheres no que diz respeito às hierarquias dos ritos matrimoniais. Casei com

Revista Interinstitucional Artes de Educar. Rio de Janeiro, V. 4 N. 3 - pag 679-700 (out/2018 - jan/ 2019) 
filho de gaúchos, que migraram para o Nordeste para fugir da ditadura militar, e minha mudança para Porto Alegre é motivada, principalmente, pelas normas impostas socialmente às mulheres: acompanhante de travessias dos cônjuges. Ao chegar no Sul do país, região em que o processo de migração para o branqueamento da raça, especialmente de alemães e italianos, obteve "mais sucesso" (SEYFERTH, 2015), começo a descobrir enquadramentos que emolduram a identidade nordestina, tanto pelo que relatam de mim, quanto pelo compartilhamento com outros nordestinos acerca das vivências no Sul.

\section{Enquadramentos dos nordestinos no sul}

Em 1996, nos primeiros dias de aula do curso de graduação em jornalismo, na PUCRS, após a produção de texto de auto-apresentação, o professor, com tom de estranheza, fez os seguintes questionamentos: Você é nordestina? Mas, você não tem cara de Nordestina?. Tais perguntas me causaram certa desorientação, pois algo que eu não conhecia de mim mesma estava sendo dito. Mas qual é a cara de Nordestino?, retruquei. Ora, os nordestinos têm cabeça chata, porque dormem de rede. São baixos e magros e têm pele escura. Essa mistura de índio e negro, acho!, respondeu. Se a interrogação me causou surpresa, a descrição do enquadramento ajuda a entender as molduras que formam o personagem do nordestino em outras regiões, especificamente o Sul, e os efeitos que tais práticas discursivas causam na organização social.

Embasando-se nas reflexões de Foucault, Butler (2015, P.17) concebe o sujeito como efeito de normas que, quando repetidas, produzem e deslocam os termos por meio dos quais os sujeitos são reconhecidos, o que faz com que exista 'vidas' que dificilmente - ou, melhor dizendo, nunca - são reconhecidas como vidas. Assim, segundo a autora, os enquadramentos são modelados por discursos que classificam, hierarquizam e enquadram a vida de mulheres, mulçumanos, gays, imigrantes e refugiados de guerra e atuam para diferenciar as vidas que podemos apreender daquelas que não podemos, gerando assim ontologias específicas de sujeito.

Trazendo para o contexto brasileiro, podemos pensar nos enquadramentos das identidades regionais e suas repercussões nas relações políticas, sociais e econômicas. Ao nos deparamos com os termos que compõem a gramática pelos quais nordestinos são 
reconhecidos aqui no Sul, percebe-se que são tratados como uma massa homogênea de corpos que representam riscos, por não estarem adequados ao processo civilizatório, nos quais se imbricam questões raciais e de gênero. Aqui nos transformamos, geralmente, em nortistas. É comum que os habitantes do Sul do país não diferenciem a população do Norte e do Nordeste, e a ambos são atribuídas características corporais e psíquicas peculiares: estatura baixa, pele escura e carentes. Corpo mole para o trabalho, definição do famoso preguiçoso, usado especialmente para se referir aos baianos. Gente de sotaque engraçado, que fala cantando e lento no pensar por possuir pouca inteligência. Assim, se imbricam pobreza e carência.

Tais enquadramentos causam efeitos diversos no processo de aparição pública e divide as populações entre aquelas pessoas por quem lamentamos e aquelas por quem não lamentamos (BUTLER, 2015,p. 64). Ao pensar a distribuição desigual do luto público como uma questão política de grande importância, a filósofa contribui para pensarmos como nos processos de migração se intercruzam as questões de identidade regionais, que hierarquizam vidas que podem ser exploradas em condições de trabalho escravo. Realidade que vitimiza homens e mulheres nordestinos, constatada tanto no interior de Santa Catarina, região Sul, quanto no Pará, região Norte. Reportagem divulgada pelo site Piauí ${ }^{\text {ix }}$ mostra o aliciamento de 22 trabalhadores piauienses para trabalhar na colheita da cebola em Bom Retiro. Submetidos a condições subumanas, eles dormiam em pedaços de espuma, em um casa de três quartos, sem água potável e com instalações sanitárias precárias. Fiscais do Ministério do Trabalho investigam ainda a denúncia de que recebiam como pagamento drogas, especialmente crack. Situação similar foi denunciada pelo documentário "Nas terras do Bem-Virá", que retrata a exploração de trabalhadores na Amazônia no contexto de práticas nocivas do Agronegócio, como a grilagem, o assassinato de muitas pessoas que oferecem resistência, a destruição de florestas, dos animais, contaminação das águas, etc. Para muitos nordestinos, é uma ida sem volta. Por lá morrem e os corpos nunca são encontrados. Contexto em que se materializa o descaso do poder público e dos grandes latifundiários com a população historicamente menos favorecida, que ao não merecer enlutamento, pode ser exposta a condições deploráveis de existência, na qual se conjugam a exploração do trabalho humano com a do meio ambiente.

Em relação às mulheres, se esse processo de migração para trabalhar na agricultura atinge com mais prevalência os homens, elas são afetadas com a mesma brutalidade. Sozinhas 
para administrar os minguados recursos, ficam em situação de abandono, tanto pela saída dos companheiros, e alguns, vitimados por assassinatos ou por constituir outras famílias, nunca voltam; quanto pela inexistência de políticas públicas que lhes assegurem proteção contra a violência de gênero e melhores condições de vida. E, assim como os homens, ficam submetidas a condições de precarização de suas vidas. As mulheres são aprisionadas pela fome, submetendo-se a trabalhos domésticos mal remunerados para garantir o sustento dos filhos.

Importa ainda destacar que o êxodo migratório em busca de melhores condições de vida também faz parte da realidade das nordestinas. Em Florianópolis, é comum encontrá-las alocadas em trabalhos ligados à atividade doméstica, como Elisa, ou na área do comércio, atividade de Fátima. Elisa migrou do Maranhão, assombrada pelo desemprego do marido. Lá atuava como pequena empreendedora na produção de decoração de festas para casamento, aniversários e outros tipos de festividade. Ao chegar na Ilha da Magia, depara-se com a falta de redes de contato e com a baixa escolaridade, o que a levou a abandonar a pretensão de dar continuidade ao negócio. Com ajuda de membros da igreja evangélica, conseguiu trabalho de merendeira em uma que empresa que terceiriza serviços para prefeitura, assumindo a função de preparar o jantar dos alunos da Educação de Jovens e Adultos.

Já Fátima, veio de Aracaju e conseguiu colocação de caixa num supermercado de porte médio. Para enfrentar o estigma de preguiça que recai sobre os nordestinos, abre mão de folgas, e está sempre disposta a trabalhar nos fins de semana. Em uma rápida conversa enquanto ela registrava as compras que eu tinha feito e, acredito que motivada pelo reconhecimento de certa irmandade de sotaque, me relatou sobre as saudades da sua terra e sobre as dificuldades que enfrenta no Sul. Aqui o povo é diferente, é muito frio, e temos que provar o tempo todos que somos trabalhadores. Veja aí! Final de semana só tem nordestino trabalhando aqui. Preguiçoso é povo daqui, desabafa.

O depoimento de Fátima nos mostra como os enquadramentos identitários, nos quais se cruzam pertencimento racial, de gênero e regional, geram intercruzamento de opressões, que Crenshaw (2002) denomina de interseccionalidade, e a luta por reconhecimento a partir de outras lentes. Nesse sentido, Butler (2015, p.198) lança o seguinte questionamento: o que é ser reconhecido?, argumentando para a necessidade de se levar em conta a ontologia do sujeito cujo reconhecimento e cuja representação está em questão. Para a autora, a noção de 
reconhecimento, faz parte da própria prática de ordenar e regular os sujeitos de acordo com normas pré-estabelecidas (Idem, p.202). Movimento que corre o risco de reconsolidar o sujeito do reconhecimento. No caso de Fátima, ao lutar por reconhecimento, submete-se a flexibilização dos seus direitos trabalhistas, o que, de certa forma, perpetua a maximização da condição de precariedade da trabalhadora nordestina em detrimento da minimização da do sulista, que, por ser enquadrado por outras lentes, não precisa se submeter a determinadas condições de trabalho.

Os discursos que compõem a moldura das identidades nordestinas são articuladas em diversas direções, justificando tanto contratação de trabalhadores e trabalhadoras em condições precárias, quanto para lhes atribuir responsabilidade por questões ambientais, retomando certa linha de continuidade com perspectivas higienistas e discriminatórias associadas a moradores dessa região, como aconteceu em Florianópolis, em 2016, no período de alta estação. Época do ano em que a população triplica, além dos 447,8 mil habitantes, a ilha recebe turistas e vendedores ambulantes. Na ocasião, algumas praias, que são o grande atrativo, apresentavam condições perigosas para receber os banhistas, por excesso de coliformes fecais na água, situação que atingia 74 pontos do litoral, de acordo com documento divulgado pela Fundação Estadual do Meio Ambiente (Fatma), o que levou muitos turistas a passarem mal. Desconsiderando a questão, o então presidente do Sindicato dos Hotéis, Restaurantes, Bares e Similares de Florianópolis ${ }^{\mathrm{x}}$, Tarcísio Schmidt, alegando que as doenças provocadas em alguns turistas era decorrente do consumo de queijos coalho, comercializado pela população nordestina.

\section{Considerações finais}

Pelbart (2017), no artigo Estamos em Guerra, texto de abertura da série de cordéis político Pandemia, nos chama a atenção para a necessidade de "fazer proliferar uma outra sensibilidade micropolítica, macropolítica, biopolítica, ecopolítica, cosmopolítica, dar nome aos bois, romper um consenso que nos quer abduzir a capacidade de pensar". E é nesse movimento que a Epistemologia das Piabas se insere: um pensar com as mulheres e suas diferentes realidades e enquadramentos. Um pensar em movimento com olhar crítico sobre o presente, refletindo acerca dos limites delegados, a nós latino-americanas, pelas teorias 


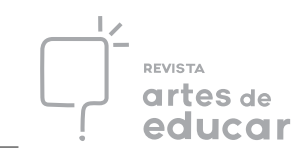

feministas produzidas a partir de contextos europeus. Movimento que não se reduz a negá-las ou refutar sua importância, mas de confrontá-los com seus próprios limites, bem como dialogar com as que ajudam a expandir o pensar.

Nesse sentido, cabe reconhecer que as categorias mulher e gênero foram centrais para desvelar as desigualdades que se constituíam a partir do processo de normatização de aspectos biológicos, mas têm limites para entender os processos de racialização de mulheres indígenas, negras e nordestinas e as relações entre gênero e ecologia em contextos decoloniais. Trata-se de um movimento de rompimento com a ideia de sujeito universal e de localização e contextualização das vidas e das condições de maximização da condição de precariedade de determinadas vidas em detrimentos de outras para enfrentar as guerras que se continuam presentes.

As guerras historicamente se constituem na luta pela sobrevivência e demarcação de poder, configuradas por perdas e ganhos, embates entre grandes e pequenos, que deixam rastros de massacres, genocídios e muita violência. $\mathrm{O}$ movimento pelo bem-viver exige uma profunda reflexão sobre os parâmetros de igualdade de esperança de vida entre humanos e não humanos. A esperança de vida se constitui na possibilidade do alcance ao bem-estar material de forma equilibrada, qualidade de vida, sustentabilidade e responsabilidade com o meio ambiente. Entre humanos, ressalta-se o bem-estar subjetivo, que garanta a pluralidade de sobrevivência das diferenças em suas expressões de gênero, origem, crença, sexualidade, dentre outros. Para as mulheres e as piabas as ameaças humanas e naturais resultam em resistências, no ecoar de gritos/gestos/escritas/movimentos em correntezas.

\section{REFERÊNCIAS}

ALVES, Rubem. Entre a ciência e a sapiência: o dilema da educação. São Paulo: Edições Loyola, 1999.

BATURITÉ, Wikipédia. Disponível em: https://pt.wikipedia.org/wiki/Baturit\%C3\%A9. Acesso em: 16 de setembro de 2018.

BUTLER, Judith. Quadros de Guerra. Quando a vida é passível de luto? $1^{\text {a }}$ Edição. Rio de Janeiro. Civilização Brasiliense. Tradução: Sérgio Lamarão e Arnaldo Marques da Cunha. 2015. 
BRASIL. IBGE. Pesquisa Nacional por Amostra de Domicílio Contínua (PNAD). 2017.

Disponível: https://www.ibge.gov.br/estatisticas-novoportal/sociais/trabalho/17270-pnadcontinua.html?=\&t=0-que-e. Acessado em: 1 de dezembro de 2018.

CRENSHAW, K. Documento para o encontro de especialistas em aspectos da discriminação racial relativos ao gênero. Revista estudos feministas, v. 10, n. 1, 2002.

FERREIRA, A. B. H. Novo dicionário da língua portuguesa. Segunda edição. Rio de Janeiro. Nova Fronteira. 1986.

FONSECA, Cláudia. Prefácio In: PEDRO, Joana Maria \& GROSSI, Miriam Pillar (orgs). Masculino, feminino, plural: gênero na interdisciplinaridade. Florianópolis: Ed. Mulheres, 2006, p. 15-20.

FOUCAULT, Michel. Em defesa da sociedade. São Paulo. Martim Fontes, 1999.

JONES, SH; ADAMS, TE; ELLIS, C; OLIVEIRA, MAO; JARAMILLO, NJ. Handbook of Autoethnography (Coleção Queer). 2013. Left Coast Press, Walnut Creek: 736p.

LUGONES, María. Rumo a um feminismo descolonial. Florianópolis: Estudos Feministas, 22(3): 935-952, setembro-dezembro, 2014.

2008. No.9: 73-101.

Colonialidad y Género. Bogotá - Colombia: Tabula Rasa. Julio-diciembre,

OLIVEIRA, Kleber Fernandes; JANNUZZI, Paulo de Martino. Motivos para migração no Brasil e retorno ao Nordeste:padrões etários, por sexo e origem/destino. São Paulo em Perspectiva, v. 19, n. 4, p. 134-143, out./dez.

PELBART, Peter Pál. Estamos em guerra. Série Pandemia.Rio de Janeiro. N-1 edições. 2017. Disponível: https://issuu.com/n-1publications/docs/1_estamos_em guerra pelbart. Acesso em: 10 de outubro de 2018.

RAGO, Margareth. Epistemologia feminista, gênero e história. In: PEDRO, Joana Maria \& GROSSI, Miriam Pillar (orgs). Masculino, feminino, plural: gênero na interdisciplinaridade. Organizado por Joana Maria Pedro e Miriam Pillar Grossi. Florianópolis: Ed. Mulheres, 2006, p. 21-41.

SEYFERTH, Giralda. Pensamento social no Brasil, por Giralda Seyferth: notas de aula. / BAHIA, Joana \& MENASCHE, Renata \& ZANINI, Maria Catarina Chitolina - Porto Alegre: Letra\&Vida, 2015.

Tiburi, Marcia. Lugar de fala e lugar de cor. Revista Cult. Março.2017.

Disponível:https://revistacult.uol.com.br/home/lugar-de-fala-e-etico-politica-da-luta/.

Revista Interinstitucional Artes de Educar. Rio de Janeiro, V. 4 N. 3 - pag 679-700 (out/2018 - jan/ 2019) 
Acessado em: 10 de dezembro de 2018

SPIVAK, Gayatri Chakravorty, 1942. Pode o subalterno falar? tradução de Sandra Regina Goulard Almeida, Marcos Pereira Feitosa, André Pereira Feitosa. Belo Horizonte: Ed. UFMA, 2010 .

WALSH Catherine. Lo Pedagógico y lo Decolonial: Entretejiento Caminos. In: WALSH, Catherine (Org). Pedagogías Decoloniales. Prácticas insurgientes de (re) existir y (re) vivir. Tomo I. Quito: Ed. Abya Yala, Tomo I. 2013, p.23-68.

\section{Entrevista:}

MOREIRA, Matheus Moreira; DIAS, Tatiana. O que é 'lugar de fala' e como ele é aplicado no debate público. Entrevistados: Rosane Borges, Renan Quinalha, Joice Berth. Portal Nexo. Janeiro 2017. Disponível: : https://www.nexojornal.com.br/expresso/2017/01/15/O-que$\% \mathrm{C} 3 \% \mathrm{~A} 9-\% \mathrm{E} 2 \% 80 \% 981$ ugar-de-fala $\% \mathrm{E} 2 \% 80 \% 99$-e-como-ele- $\% \mathrm{C} 3 \% \mathrm{~A} 9$-aplicado-nodebate-p\%C3\%BAblico. Acessado em: 10 de dezembro de 2018.

Vídeos:

GLOBO. Vídeo Tecnologia acelera a criação de lambari de cativeiro em SP. Globo Rural. Disponível em: https://globoplay.globo.com/v/6664078/. Acesso em: 16 de setembro de 2018.

DOCUMENTÁRIO. Terras do Bem-Virá. Direção de Alexandre Rampazzo. 2011 Disponível em: https://www.youtube.com/watch?v=VibNE-8dN7o. Acesso: 18 de outubro de 2018.

\footnotetext{
${ }^{\text {i }}$ Docente da Universidade da Integração Internacional da Lusofonia Afro-Brasileira. Pós-doutorado no Programa Interdisciplinar em Ciências Humanas da Universidade Federal de Santa Catarina.

ii Doutoranda no Programa de Pós-Graduação em Educação da Universidade Federal de Santa Catarina.

iii Para Walsh (2013), os Estudos Decoloniais inscreve-se como um lugar de enunciação crítica à epistemologia eurocêntrica e a emergência do reconhecimento dos distintos saberes advindos das experiências sociais que surgem nas e com as diferentes vivências dos sujeitos, assim constitutivas de diferentes aprendizagens e de espaços de pensamento.

iv Para Rosane Borges, o lugar de fala é a posição de onde olho para o mundo para então intervir nele. É um espaço que se constitui com e no diálogo, a partir do reconhecimento dos marcadores sociais, dos lugares sociais que cada um ocupa, que lhe permite ver a sociedade sob determinadas perspectivas. Marcia Tiburi chama a atenção para a necessidade do diálogo e do reconhecimento do outro. Se o lugar de fala é abstrato e silencia o outro onde deveria haver um diálogo, então ele já não é mais um lugar político, mas um lugar autoritário que destrói a política no sentido das relações humanas que visam o convívio e a melhoria das condições da vida em sociedade.

${ }^{\vee}$ Crenshaw (2002) situa que o princípio da interseccionalidade trata especificamente da forma pela qual o racismo, o patriarcalismo, a opressão de classe e outros sistemas discriminatórios criam desigualdades básicas que estruturam as posições relativas de mulheres, raças, etnias, classes e outras. Além disso, a interseccionalidade trata da forma como ações e políticas específicas geram opressões que fluem ao longo de tais eixos, constituindo aspectos dinâmicos ou ativos do desempoderamento (CRENSHAW, 2002: 177).

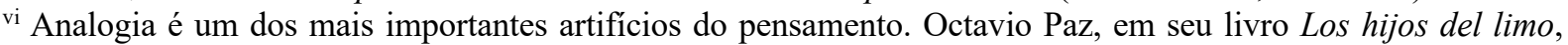
afirma que a analogia torna o mundo habitável. Ela é o reino da palavra como essa ponte verbal que, sem suprimi-las, reconcilia as diferenças e oposições. A analogia nos permite caminhar do conhecido ao desconhecido. É assim: eu conheço A mas nada sei sobre B. Sei, entretanto, que B é análogo a A. Assim, posso
} 
concluir, logicamente, que B é parecido com A. (...) É, em grande medida, graças às analogias que o conhecimento acontece. (...) Um bom professor tem de ser um mestre de analogias. Uma boa analogia é um flash de luz (ALVES, 1999: 87-88).

vii Sobre produção de lambari em cativeiro, ver em: vìdeo tecnologia acelera a criação de lambari de cativeiro em SP. Globo Rural. Disponível em: https://globoplay.globo.com/v/6664078/. Acesso em: 16 de setembro de 2018.

viii $\mathrm{O}$ nome Redenção vem do fato de que este foi o primeiro município do Brasil a libertar os escravizados (antiga vila do Acarape. Do tupi-guarani acará + pe, caminho dos peixes). Redenção era distrito de Baturité, sendo emancipado em 1868.

ix Sob o título, Piauienses são resgatados em condições de escravidão em Santa Catarina, a matéria foi divulgada no dia 7/12/2018, pelo site Acesse Piauí. Disponível: https://www.acessepiaui.com.br/noticia/11369/Piauiensessao-resgatados-em-condicoes-de-escravidao-em-Santa-

Catarina?fbclid=IwAR3P6H4XlsCzBccKGYDmkg0KduY3Z3sT1-4tWz10pkQfOi8xn4ffULLDdec. Acesso em: 10 de dezembro de 2018.

x Sob o título, Poluição nas praias de SC é culpa do queijo coalho dos Nordestinos, foi divulgada no site Pragmatismo Político, em 26 de janeiro de 2016. Disponível: https://www.pragmatismopolitico.com.br/2016/01/poluicao-nas-praias-de-sc-e-culpa-do-queijo-coalho-dosnordestinos.html. Acessado em: 30 de janeiro de 2016 